\title{
Patients' Satisfaction with Type 2 Diabetes Care and its Relation to their Glycaemic Control-Primary Health Care Setting, Port Said, Egypt
}

\author{
Sameh F. Ahmed*, Hassan A. Abdel-Wahid, Rehab A. Mohamed, \\ Yara M. Mohammad
}

Department of Family Medicine, Faculty of Medicine, Suez Canal University, Ismailia

\begin{abstract}
Background: Research has identified a clear link between clinical outcomes and patient satisfaction especially in chronic diseases like diabetes, where a wide range of needs and expectations exists. Satisfaction affects the timely, efficient, and patient-centred delivery of quality health care. Aim: To assess patients' satisfaction with type 2 diabetes care and its relation to their glycaemic control. Patients and Methods: Analytic cross sectional study with a total of 72 patients $\geq 18$ years old with type 2 diabetes who attend Port Fouad urban family health centre, Port Said city, Egypt were invited to complete 18 items, Patient Satisfaction Questionnaire (PSQ-18) to determine their satisfaction and its relation to the degree of HbA1c control. The questionnaire contained 7 domains to identify patients, doctors and practice determinants of satisfaction. Results: $60 \%$ of type 2 diabetic patients were satisfied with the provided health care services. Doctor's communication ranked the highest satisfaction level among other factors followed by satisfaction with consultation time and appropriateness of consultation room. Meanwhile, the study revealed a proportional relationship between overall patients' satisfaction and controlled HbA1c. Conclusion: There was a clear link between patients' satisfaction with type 2 diabetes care and improvement of their glycemic control.
\end{abstract}

Keywords: Type II diabetes, HbA1c, patient's satisfaction, primary care

\section{Introduction}

Patient satisfaction is an important and commonly used indicator for measuring the quality in health care. Patient satisfaction affects clinical outcomes, patient retention, and medical malpractice claims. It affects the timely, efficient, and patientcentred delivery of quality health care. There was no homogeneous definition of patient satisfaction, since satisfaction concerns different aspects of care or set- tings, as well as care given by various professions $^{(1)}$. Thus, the interpretation of patients' satisfaction as an overall score is often difficult, but comparisons over defined dimensions of care being more appropriate ${ }^{(2)}$. Many studies have focused on the main components including patients', physicians' and practices' characteristics, which influenced patients' ratings of satisfactions(3). However, previous studies have not identified those factors that are most important. Moreover, in re-

*Correspondent Author: ymddsm@gmail.com 
cent years, the characteristics of the external environment have been also considered as additional factors influencing individual evaluation(4). Improving the quality-of-care for patients with chronic conditions like diabetes mellitus became an important focus of the health-care system and policy. The focus on diabetes mellitus is increasing because it becomes a major public health problem with a wide range of needs and expectations(5). In 2013 about 382 million people were estimated to have diabetes with a global prevalence of $8.3 \%$. North America and the Caribbean are the regions with higher prevalence, 36,755 people with diabetes (11\%) followed by the Middle East and North Africa with 34,571 people with diabetes (9.2\%). There were 7.5 million cases of diabetes in Egypt in $2013^{(6)}$. Diabetes mellitus is a complex, chronic illness requiring continuous medical care with multifactorial risk reduction strategies beyond glycemic control. Ongoing patient selfmanagement, education and support are critical to preventing acute complications and reducing the risk of long-term complications. Significant evidence exists that supports a range of interventions to improve diabetes outcomes( $(7)$. Diabetes is associated with serious long-term complications including microvascular and macrovascular disease, which impose an additional socio-economic burden and account for substantial healthcare costs. Improved glycemic control in people with diabetes reduces the risk of long-term complications $^{(8)}$. The quality of diabetes care is widely sub-optimal and most of the interventions depend on active involvement and participation of patients. Thus working through patient satisfaction may be an important way of improving diabetes care $^{(9)}$ Some studies have highlighted that satisfaction strongly increases when care is provided in accordance with the clinical standard procedures ${ }^{(10)}$. Different psychosocial and behavioral hypotheses have been proposed to explain the association between patients' satisfaction and medical outcomes. Empirical findings typically suggest a positive relationship between health outcomes and satisfaction with care. An alternative theory suggested that patient satisfaction may be both a consequence and a determinant of health status $^{(11)}$. The present study was carried out to identify factors that influence satisfaction with type 2 diabetes care in Egypt's current health care system where 72 percent of all healthcare costs are covered out of pocket despite that more than half of the population has access to some form of health insurance ${ }^{(12)}$. As well, to find any relation between this satisfaction and the extent of glycemic control.

\section{Patients and Methods}

A cross-sectional study was performed in one of two urban primary health care centres. Port Fouad district, Port Said city, Egypt. This centre provides a package of primary care services including diabetes care, 8 hours daily, 5 days a week to about 34000 individuals. This centre holds a diabetic clinic, which provides comprehensive diabetes care running by qualified family physicians. For inclusion in the study, 72 men and women aged 18 years or above with known typez diabetes who attended the health centre for diabetes follow up were selected. This age group represents the majority of type 2 diabetics attending the centre. The representative sample was selected by simple randomization using simple randomization table after enlisting type 2 diabetic patients who attended the Port Fouad primary health care centre for follow up visits. Patients with type 1 diabetes, insulin dependent type 2 diabetics, mental retardation, Alzheimer's disease, those attending for concomitant acute illness and patients 
who refused participation in the study were excluded.

Measurement of patient satisfaction: Patient satisfaction was assessed using 18 items structured, interviewer-administered Patient Satisfaction Questionnaire (PSQ-18) $^{(14)}$, which has undergone a series of successful validations. The PSQ-18 questionnaire has one total score that measures overall satisfaction and separate scores for each of six different subscales (technical Quality, interpersonal Manner, communication, financial aspects, time spent with doctor, accessibility and convenience). Some PSQ-18 items were worded so that agreement reflects satisfaction with medical care, whereas other items are worded so that agreement reflects dissatisfaction with medical care. All items were scored so that high scores reflect satisfaction with medical care. After item scoring, items within the same subscale have been averaged together to create the 7 subscale scores. Cut-offs for the total scores were decided by the researcher as $<60 \%=$ "not satisfied"; $60-80 \%$ as "moderately satisfied" and $>80$ as "highly satisfied". The questionnaire was translated from English to Arabic by a translator in a private office. Three doctors including one of the researchers have been trained on using the questionnaire to avoid interpersonal bias. As well, a pilot study (10 patients) has been conducted to test the wording and reliability of the questionnaire.

Measurement of diabetes control: Control of blood glucose was assessed by measuring $\mathrm{HbA}_{1} \mathrm{c}$, the same day of interviewing the patient. Mindray enzymatic on BS-200 analyzer was used and $6.5-7.0 \%$ was considered the normal range of glycemic control(15)

Study design: Data were collected from patients attending their diabetes followup over a 3-months period (January-March 2016) after a verbal informed consent. Pa- tients were interviewed face to face by three family physicians working at Port Fouad primary health care center.

\section{Statistical Analysis}

The Statistical Package for Social Sciences (SPSS version 16.0) was used for data analysis. Descriptive statistics and appropriate significance tests were used according to types of variables. Chi-square test was used to test the significance of difference between the categorical variables e.g. sex. Pearson's correlation analysis was used to test the significance of linear association between $\mathrm{HbA} 1 \mathrm{c}$ and total patient satisfaction questionnaire (PSQ-18) scores. Multiple linear regression was used to detect the predictors of the patients' satisfaction among the study group.

\section{Results}

Patients' socio-demographics

The study included 72 type 2 diabetic patients from an urban area (Port Fouad). Their age ranged from 34-76 years with mean equal to $54.3 \pm 11.3$. There were more females (59.7\%) than males (40.3\%) and most females were housewives (59.7\%). Most the study people were educated with intermediate education ranked first (25\%), followed by primary school (23.6\%) and higher education (18.1\%). There were four socioeconomic categories that included very low (6.9\%), low (36.1\%), middle $(52.8 \%)$ and high category (4.2\%).

HbA1c control levels of the study group: As shown in Figure 1, the minority of the studied patients were controlled (1.4\%) as defined level of $\mathrm{HbA} 1 \mathrm{c}$ below $7 \%$.

Overall patients' satisfaction of diabetes care: The study revealed that $60 \%$ of patients were satisfied with the provided diabetes care but with variation in their degree of satisfaction as shown in Figure 2 
Table 1: Baseline Characteristics of the Study Group ( $n=72)$

\begin{tabular}{|l|c|c|}
\hline Characteristics & No. & $\%$ \\
\hline $\begin{array}{l}\text { Age (mean+ SD) } \\
\text { Sex }\end{array}$ & $54.3 \pm 11.3$ & \\
- Male & 29 & 40.3 \\
- Female & 43 & 59.7 \\
Educational level & & \\
- Illiterate & 9 & 12.5 \\
- Read and write & 18 & 25 \\
- Primary school & 4 & 23.6 \\
- preparatory & 11 & 5.6 \\
- Secondary & 13 & 18.3 \\
- University/higher education & & \\
Occupation & 43 & 59.7 \\
- Nonworking/housewife & 3 & 4.2 \\
- Unskilled manual worker & 4 & 5.6 \\
- Skilled manual work- & 6 & 8.3 \\
$\quad$ er/farmer & 16 & 22.2 \\
- Trades/business & & \\
- Semi-professional/clerk & & \\
\hline
\end{tabular}

SD: standard deviation No: number

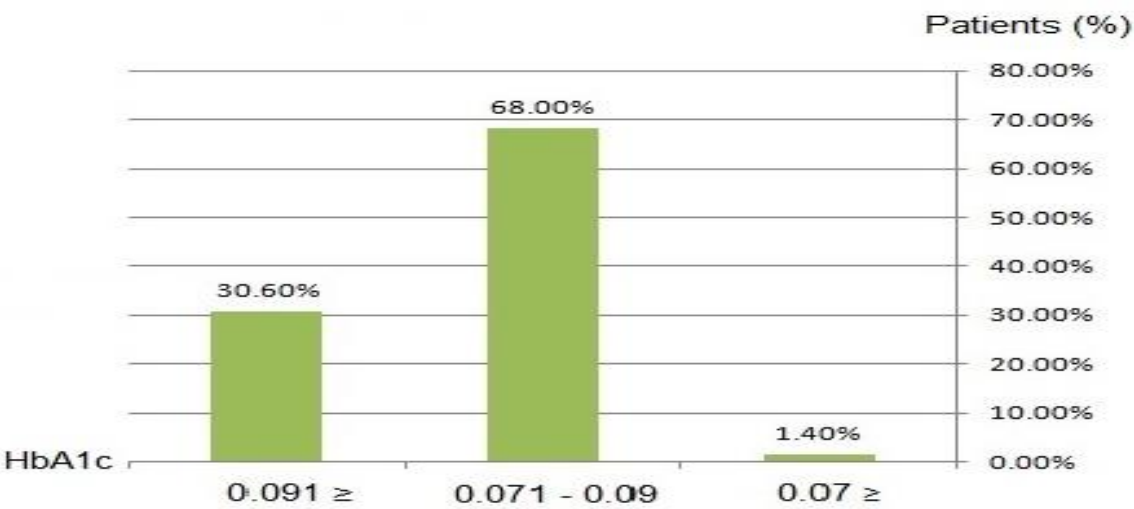

Figure 1: Frequency distribution of $\mathrm{HbA1C}$ among study group

Satisfaction with different domains of PSQ18: About 47\% of patients were moderately satisfied with technical quality while $43 \%$ of patients were not satisfied. Nearly $43 \%$ of patients were highly satisfied of interpersonal manner. More than half of patients (57\%) were moderately satisfied with communication. There were about $48.6 \%$ of patients moderately satisfied with financial aspects, whereas $34.7 \%$ were not satisfied. Regarding time spent with doctor, about $57 \%$ of patients were moderately satisfied while 39\% were not satisfied. Approximately $55.6 \%$ of patients were moderately satisfied and $30.6 \%$ were highly satisfied with accessibility and convenience of health care services. In all patients' satisfaction domains, there was no significant difference between males and females (Table 2).

Predictors of glycemic control: Multiple regression analysis was conducted between glycosylated $\mathrm{Hb}$ (HbAlc) as dependant variable and the following independent 
variables: General satisfaction, Technical quality, Interpersonal manner, Communication, Time spent with doctor, Financial aspects and Accessibility and Convenience. The results of regression analysis revealed that technical quality domain of
Patient Satisfaction Questionnaire (PSQ), Accessibility and Convenience of health care were the only significant predictors of $\mathrm{HbA1c}$ with negative linear association. (Table 3).

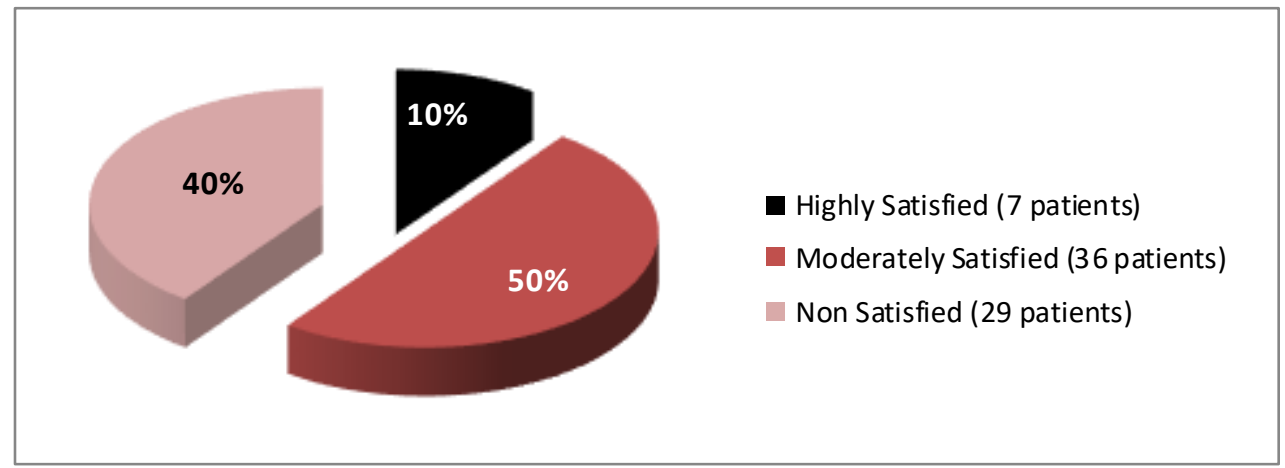

Figure 2: Categories of satisfaction with diabetes 2 care

Table 2: Frequency Distribution of Patients' Satisfaction regarding different domains

\begin{tabular}{|c|c|c|c|c|c|c|c|c|}
\hline & \multicolumn{3}{|c|}{ Males } & \multicolumn{3}{|c|}{ Females } & \multirow[b]{2}{*}{ 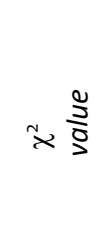 } & \multirow[b]{2}{*}{$a$} \\
\hline & 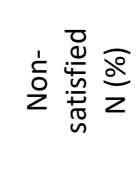 & 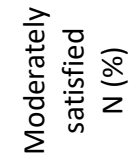 & 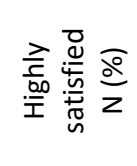 & 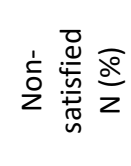 & 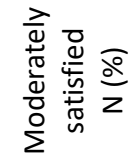 & 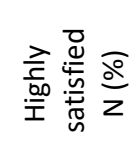 & & \\
\hline \multirow{6}{*}{$\begin{array}{l}\text { - Technical Quality } \\
\text { - Interpersonal manner } \\
\text { - Communication } \\
\text { - Financial aspects } \\
\text { - Time spent with doctors } \\
\text { - Accessibility and Con- } \\
\text { venience }\end{array}$} & $15(48.4)$ & $12(35.3)$ & $2(28.6)$ & 16 (51.6) & 22 (64.7) & 5 (71.4) & 1.545 & $0.499 *$ \\
\hline & $8(47.1)$ & $8(33.3)$ & $13(41.9)$ & $9(52.9)$ & $16(66.7)$ & $18(58.1)$ & 0.842 & 0.645 \\
\hline & $11(45.8)$ & $14(34.1)$ & $4(57.1)$ & $13(54.2)$ & 27 (65.9) & 3 (42.9) & 1.847 & $0.427 *$ \\
\hline & $8(32.0)$ & 15 (42.9) & $6(50.0)$ & $17(68.0)$ & $20(57.1)$ & $6(50.0)$ & 1.280 & 0.529 \\
\hline & $11(39.3)$ & 17 (41.5) & 1 (33.3) & $17(60.7)$ & $24(58.5)$ & $2(66.7)$ & 0.232 & $1.000 *$ \\
\hline & $3(30.0)$ & $18(45.0)$ & $8(36.4)$ & $7(70.0)$ & $22(55.0)$ & $14(63.6)$ & 0.911 & $0.666^{*}$ \\
\hline
\end{tabular}

$\chi^{2}=$ Chi- square; ${ }^{*}=$ Fisher's test

Table 3: Multiple regression analysis: Predictors of glycemic control among study group

\begin{tabular}{|l|c|c|c|c|c|}
\hline Constant & $\begin{array}{c}\mathrm{B} \text { (regression } \\
\text { coefficient) }\end{array}$ & $\mathrm{SE}$ & $95 \% \mathrm{Cl}$ & $\mathrm{T}$ & $\mathrm{P}$ \\
\hline - General Satisfaction & 13.190 & 1.758 & $-0.44--0.30$ & 30.061 & 0.000 \\
- Technical Quality & -0.004 & 0.840 & $-0.55--7.27$ & -0.695 & 0.489 \\
- Interpersonal Manner & -0.017 & 1.354 & $-2.87--0.39$ & -2.557 & 0.013 \\
- Communication & -0.008 & 0.795 & $-0.28--4.24$ & -1.775 & 0.081 \\
- Time spent with doctor & -0.008 & 1.693 & $-1.43--0.10$ & -1.456 & 0.150 \\
- Financial Aspects & 0.001 & 0.643 & $-0.29--3.71$ & 0.137 & 0.892 \\
\hline
\end{tabular}

Dependent Variable: HbA1c 
Relation between level of satisfaction and degree of glycemic control: Scheffe (Post Hoc Test) was conducted to determine the significance of difference between satisfaction categories regarding glycosyl- ated hemoglobin (HbA1c). The results revealed that non-satisfied category was significantly different from each of the other two categories (highly and moderately satisfied categories) (Table-4).

Table 4: One way analysis of ANOVA the significance of difference between different satisfaction categories regarding levels of glycated haemoglobin (HbA1c)

\begin{tabular}{|l|c|c|c|}
\hline \multicolumn{1}{|c|}{ Satisfaction Category } & N & Mean & SD \\
\hline Highly Satisfied & 7 & 7.6143 & 0.75151 \\
Moderately Satisfied & 36 & 8.0056 & 0.60093 \\
Non-Satisfied & 29 & 9.4517 & 0.67221 \\
\hline
\end{tabular}

$F=48.575$

\section{Discussion}

This cross- sectional study was conducted to identify patients' satisfaction with type 2 diabetes care, factors that might influence this satisfaction and association between this satisfaction and the degree of glycemic control as measured by HbA1c. About $60 \%$ of the respondents showed overall satisfaction with the provided diabetes care although their glycemic control as measured by $\mathrm{HA}_{1} \mathrm{C}$ was only $1.4 \%$. This unexpected result might be due to expressing their satisfaction in relation to the process of care not to the level of $\mathrm{HbA} 1 \mathrm{C}$ as an outcome measure of care and glycemic control. Another explanation might be a deficiency in health education provided to these patients and lack of their awareness towards the meaning of $\mathrm{HbA} 1 \mathrm{C}$ control as one of the outcome measures that reflect quality of care. The degree of satisfaction was clearly different regarding various domains. The study revealed that $57 \%$ of patients were satisfied with technical quality domain, approximately $65.3 \%$ were satisfied with service cost, while $86 \%$ of patients were satisfied with accessibility and convenience of the provided services. In Kuwait, AlDousari et al. (2008) reported that patients' satisfaction ranged from $75.2 \%$ to $78.4 \%$ as low satisfaction was scored for some physicians' services particularly for physicians' medical skills and poor satisfaction with buildings while pharmacy services scored the highest satisfaction score $^{(16)}$ Ramirez et al. (2005) noted that every ten patients considered that their medical consultation problems were solved and that the health-care provider quality was satisfactory(17). In Mexico, Doubova et al. (2009) found that only half of diabetic patients were satisfied with their provided primary health care services $^{(18)}$ Kamien et al. (1995) found that $90 \%$ of diabetic patients reported their satisfaction toward primary care in Austral$\mathrm{ia}^{(19)}$. This wide range of difference in overall patients' satisfaction among the previous studies may reflect differences in economic status, culture, and people's expectations In the present study females $(59.7 \%)$ constituted the majority of the studied population compared to males (40.3\%). This might be due to more utilization of a wider package of health services provided to ladies and their kids through primary health care centers. In addition, the morning working hours of the primary health care centers might be more suitable visiting hours as most of the ladies in this particular district were house wives. But there was no significant difference between both genders regarding overall satisfaction. This result is in accordance 
with that reported by Moemen (2008) who found no association between patients' satisfaction and gender regarding provided health care ${ }^{(20)}$. However, AlDousari et al. in Kuwait found that female patients experienced higher satisfaction than males, ${ }^{(16)}$ while Al-Eisa et al. (2005) reported that males had significantly higher satisfaction than females(21) Thiedke (2007) pointed out that there was a controversy regarding the relation between patient's gender and his/her satisfaction. As she explained, this might be due to differences in gender-roles within societies $^{(22)}$. In Egypt, there is a shared socioeconomic responsibility between males and females towards their family which might explain the absence of relationship between gender and patients' satisfaction. The present study revealed a negative linear relationship between socioeconomic status and patients' satisfaction. This might be explained as diabetic patients with higher socioeconomic level have wider choices to obtain better private health care services other than primary health care. The present study also showed a negative linear relationship between educational level of the respondents and their satisfaction with type 2 diabetes services provided in primary health care. This finding is in agreement with several studies ${ }^{(23-25)}$. This may be explained by that the highly educated diabetics are more demanding, have higher expectations and are more aware of their rights than the less educated patients who may be less demanding and less aware of high quality health care available in their community. On the other hand Thiedke noted that unemployed individuals and those with lower socioeconomic status tended to be less satisfied with their health care $^{(22)}$. The results illustrated that about $57 \%$ of patients were moderately satisfied and $9.7 \%$ were highly satisfied with the physicians' communication skills. Nearly
$51 \%$ of patients were satisfied with their doctors' interest in what the patients told them. While about $40 \%$ of patients were dissatisfied with provision of little information about the reason for medical tests by the doctors. However, Al Shahrani et al. noted that Communication skills ranked the highest satisfaction level among other aspects of care in both diabetic and Family Medicine clinics (86.4\% and 90\%) respectively ${ }^{(11)}$. Moreover, in Kuwait, Al-Doghaither et al. (2005) reported that PHC physician's communication skills were strong and important correlates of patient's satisfaction $^{(25)}$. The presence of communication gaps between diabetic patients and their family physician leads to their dissatisfaction. When patients are well-informed and participate in treatment decisions, their anxiety decreases and their therapeutic adherence improves, thus increasing the chances of getting better health outcomes $^{(17,26)}$. In a study by Acharya \& Acharya (2003), $82.8 \%$ of the respondents showed that the approach of the doctor is personal( ${ }^{(27)}$, while in the present study about $43 \%$ of patients were highly satisfied and $33.3 \%$ were moderately satisfied with the interpersonal manner of their physicians. The results showed that approximately $65 \%$ of the respondents expressed that their doctors treated them in a very friendly and courteous manner. Nearly $57 \%$ of patients were satisfied (i.e., $47 \%$ were moderately satisfied and 10\% were highly satisfied) with technical quality of diabetes care. Although about $61 \%$ of patients were satisfied with the ability of doctors who treated them, about 62\% showed that their doctor's office was inappropriate to provide complete medical care. Several studies have looked at patients' assessment of their physician's technical skills and the effect on satisfaction, but the findings were contradictory ${ }^{(25)}$. Gouveia et al. (2005) mentioned that 30$40 \%$ of health care users' satisfaction is 
explained by the physicians' diagnostic and therapeutic skill and $40-50 \%$ by the physician-patient relationship ${ }^{(29)}$. This may be due to sick people like diabetics being more concerned with the outcome of the consultation that greatly depends on the clinical and prescribing competencies of the treating physician. Regarding service fees, more than half of the patients were satisfied (i.e., $48.6 \%$ were moderately satisfied and $16.7 \%$ were highly satisfied) with service cost. Due to many factors, many Egyptian patients are obliged to pay out of their pocket to get the medical care and this might explain the dissatisfaction of $34.7 \%$ in this study, especially where $52.8 \%$ of the respondents were of middle socioeconomic level and $36.1 \%$ were of low socioeconomic level. Regarding the time spent with doctor in the present study, about $57 \%$ of patients were moderately satisfied while $39 \%$ were not satisfied. This may be explained by the fact that the PHC has only one clinic for patients with chronic illness leading to overcrowding. Joshi K. et al. (2013) illustrated that in $75 \%$ of patients the time devoted by the doctor for consultation was only less than 5 minutes ${ }^{(30)}$. Abdelwahid et al. (2012) in their study on quality of type-2 diabetics' consultations illustrated that more attention should be given to the consultation length as patients' enablement correlates best with the duration of consultation(31). Accessibility is considered one of the pillars of primary care. The findings in our study showed that about $55.6 \%$ of respondents were moderately satisfied and $30.6 \%$ were highly satisfied with accessibility and convenience of health care services. Approximately $54.2 \%$ expressed that they had easy access to the medical specialist they needed and about 64\% found it was not hard to get an appointment for medical care. Rao et al. (2006) in their cross- sectional study on the assessments of quality of primary care; reported that the majority of patients expressed moderate satisfaction regarding accessibility $(65.3 \%)^{(32)}$. The study revealed that technical quality, accessibility and convenience of health care services were the significant predictors of $\mathrm{HbA} 1 \mathrm{C}$ which is similar to several studies. Little et al. (2003) illustrated that if doctors don't provide a positive, patient centered approach, patients will be less satisfied, less enabled, and may have greater symptom burden and use more health service resources(33). The results of the present study showed a negative linear relationship between patients' satisfaction and $\mathrm{HbA} 1 \mathrm{C}$ as a measure of glycemic control. This result is in accordance with that shown by Doubova et al. who emphasized that patient's satisfaction can greatly influence their contribution to disease management, which is important for better control of their conditions $^{(18)}$ Diabetics on the other hand, Alsharani et al. (2014) did not show any correlation between satisfaction and the degree of glycemic control(11).

\section{Limitations of the study}

Although sample size was justified according to sample size formula, a bigger sample size may give more accurate results. This study population shared nearly similar sociodemographic status. Therefore, results can only be generalized on a population with the same characteristics.

\section{Conclusion}

The present study concluded that many factors influence patient satisfaction with type 2 diabetes care with a clear proportional link between this satisfaction and the degree of glycemic control

\section{References}

1. Hornsten A, Lundman B, Selstam EK, Sandstrom $\mathrm{H}$. Patient satisfaction with diabetes care. J Adv Nurs 2005; 
51(6):609-17.

2. Kersnik J. An evaluation of patient satisfaction with family practice care in Slovenia. Int J Qual Health care 2000; 12:143-7.

3. Marshall GN, Hays RD. Santa Monica, CA: RAND Corporation. The Patient Satisfaction Questionnaire Short Form (PSQ-18) 1994; p. 7865.(repeated)

4. Grogan S, Conner M, Norman P. Willits D, Porter I. Validation of a questionnaire measuring patient satisfaction with general practitioner services. Qual Health Care 2000; 9(4):210-5.

5. Gulliford MC, Naithani S, Morgan M. Continuity of care and intermediate outcome of type 2 diabetes mellitus. Fam Pract 2007; 24(3):245-51.

6. International Diabetes Federation, IDF Diabetes Atlas, 2014, Available from: https://www.idf.org/sites/default/files/ Atlas-poster-2014 EN.pdf

7. American Diabetes Association. Diagnosis and classification of diabetes mellitus. Diabetes Care 2014; 37(Suppl. 1):S81-S9o.

8. Narayan KM, Gregg EW, FagotCampagna A, Engelgau MM, Vinicor F. Diabetes- a common, growing, serious, costly, and potentially preventable public health problem, Diabetes Res. Clin. Pract 2000; 50 (Suppl. 2) S77-84.

9. Narayan KM, Gregg EW, FagotCampagna $A$, et al. Relationship between quality of diabetes care and patient satisfaction. J Natl Med Assoc 2003; 95 (1):64-70.

10. Lantz PM, Janz NK, Fagerlin A, et al. Satisfaction with surgery outcomes and the decision process in a population-based sample of women with breast cancer. Health Serv Res 2005;40 (3):745 -67.

11. Al Shahrani A, Baraja M. Patient Satisfaction and it's Relation to Diabetic Control in a Primary Care Setting. J Family Med Prim Care 2014 ; 3(1): 5-11.

12. Egypt: 72 percent of Healthcare Costs are Out of Pocket. Available from http://www.worldbank.org/en/news/vi deo/2015/03/10/egypt-72-percent-ofhealthcare-costs-are-out-of-pocket

13. Creative research systems. Available from: http://www.surveysystem. com/ sample-size-formula.htm, Accessed in 22/4/2015.

14. Ghazwani E, Al-Jaber O. Study of satisfaction of diabetic patients attending the diabetic clinic at primary health centers in Abha city, Saudi Arabia. Int J Med Sci Public Health 2014; 3(4): 43643.

15. American Association of Clinical Endocrinologists, American College of Endocrinology. consensus statement on guidelines for glycemic control, Endocr. Pract. 8 (2002) 5-11.

16. Al-Dousari H, Al-Mutawa A, Al-Mithen N. Patient Satisfaction According to Type of Primary Healthcare Practitioner in the Capital Health Region, Kuwait. Kuwait Med J 2008; 40 (1): 3138.

17. Ramirez de la-Roche O, López-Serrano A, Barragán-Solis A, ArceArrieta E. User Satisfaction at a Social Security Institute Family Medical Center in Mexico City. Arch Med Fam 2005; 7:22-26.

18. Doubova SV, Pérez-Cuevas R, ZepedaArias $M$, Flores-Hernández $S$. Satisfaction of patients suffering from type 2 diabetes and/or hypertension with care offered in family medicine clinics in Mexico. Salud Públic a Méx 2009; 51(3): 231-9.

19. Kamien $M$, Ward A, Mansfield F, Fatovich B, Mather C, Anstey K. Type 2 diabetes. Patient practices, and satisfaction with GP care. Aust Fam Physician 1995; 24(6):1043-9, 1051.

20. Moemen MM. Patient satisfaction among attendants of outpatient clinics of different clinical departments at Alexandria main university hospital. Alexandria Bull Alex Fac Med 2008; 44(1):229- 40.

21. Al-Eisa IS, Al-Mutar MS, Radwan MM, Al-Terkit AM. Patient satisfaction with primary health care services at Capital Health Region, Kuwait. Middle East 
Journal of Family Medicine 2005; 3 (3):10- 16.

22. Thiedke CC. What do we really know about patient satisfaction? Fam Pract Manag 2007; 14(1):33-36.

23. Ayatollahi SM. Patient satisfaction from their consultant physician in Shiraz. Journal of Kerman University of Medical Science 1999; 6(30):149-56.

24. Babic-Banaszak A, Kovacic L, Mastilica M, Babic S, Ivanković D, Budac A. The Croatian health survey-patient satisfaction with medical service in primary health care in Croatia. Coll Anthropol 2001; 25(2):449-58.

25. Al-Doghaither AH. Inpatient satisfaction with physican services at King Khalid University Hospital, Riyadh, Saudi Arabia. East Mediterr Health J 2004; 10(3):358-64.

26. Stewart MA. Effective physicianpatient communication and health outcomes: a review. CMAJ 1995; 152 (9):1423-33.

27. Acharya JP, Acharya I. A study on compliance and behavioral responses of patients in an outpatient clinic. Indian J Community Med 2010; 35(1):5256.

28. Everitt $\mathrm{H}$, Williamson I, Warner $\mathrm{G}$, et al. Observational study of effect of patient centredness and positive approach on outcomes of general prac- tice consultations. BMJ 2001; 323 (7318):908-11.

29. Gouveia GC, Souza WV, Luna CF, Souza-Júnior PR, Szwarcwald CL. Health care users' satisfaction in Brazil, 2003. Cad Saude Publica 2005; 21 Suppl: 10918.

30. Joshi K, Sochaliya K, Purani S, Kartha G. Patient satisfaction about health care services: a cross sectional study of patients who visit the outpatient department of a civil hospital at Surendranagar, Gujarat. Int J Med Sci Public Health 2013; 2(3): 659-63.

31. Abdelwahid HA, Khalil KA. Quality of type-2 diabetics' consultations in Ismailia City, Egypt. Middle East Journal of Family Medicine. 2012; 10 (7): p1924.

32. Rao M, Clarke A, Sanderson C, Hammersley R. Patients' own assessments of quality of primary care compared with objective records based measures of technical quality of care: Cross sectional study. BMJ 2006; 333(7557): 19.

33. Little P, Everitt $\mathrm{H}$, Williamson I, et al. Observational study of effect of patient centredness and positive approach on outcomes of general practice consultations. BMJ 2001; 323 (7318):908-11. 